\title{
Characteristics and Mechanical Properties Changes Due to Incorporation of Aloe Vera in Polyethylene-Based Film
}

\author{
Siti Fatma Abd Karim*, Junaidah Jai, Ku Halim Ku Hamid, Abdul Wafi Abdul \\ Jalil
}

Faculty of Chemical Engineering, Universiti Teknologi MARA, 40450 Shah

Alam, Selangor, Malaysia

*Corresponding author's e-mail: sitifatma9633@uitm.edu.my

Received: 28 July 2019

Accepted: 12 June 2020

Online First: 25 August 2020

\section{ABSTRACT}

Non-degradable properties of polyethylene (PE) films due to long-chain structure cause increment of solid waste plastic. Many researchers, with different purposes, have studied the incorporation of functional materials to PE. Exploring the impact of the incorporation of aloe Vera (AV) into $P E$ films in terms of its characteristic and mechanical properties is the main objective of this paper. The films were prepared using melt-blending and hot press technique. The characterisation assessed for the PE and $P E-A V$ films were spectroscopy, crystalline phase, thermal analysis, and performance of the mechanical properties of the sample. Some of the AV functional groups disappeared upon addition with PE but has the possibility of two sharing peaks between AV and PE, which was 1472 and $2915 \mathrm{~cm}^{-1}$. Lower thermal degradation temperature $\left(T_{d}\right)$ obtained for PE-AV3 while other films found no significant changes in $T_{d}$ value, and only one peak of thermal degradation occurred for all films. The same goes for the analysis obtained from differential scanning calorimetry (DSC) data. However, the crystalline structure displayed momentous peak changes for PE with AV. The highest tensile strength (TS) obtained by PE-AV3, at once, developing the highest value of Young's modulus $(Y M)$, modulus of resilience $\left(U_{F}\right)$, and modulus of toughness $\left(U_{T}\right)$. A certain amount of AV has a substantial effect on changing the polymeric structure, especially improving the mechanical properties of PE film. Therefore, AV has the potential to become an additive for developing a new, partially degradable PE film. 
Keywords: polyethylene, aloe vera gel, film packaging

\section{INTRODUCTION}

Polyethylene is a type of synthetic polymer that has an extended chain ethylene monomer. PE has been used in many industries such as packaging, agriculture, automotive, constructions, consumer good, cosmetics, pharmaceuticals, and others. The packaging industry covers almost 50 $\%$ demand for PE in the year 2018 and expected increasing demand until the year 2026 [1]. Low cost, light, good chemical resistance, excellent processability, and raised in the mechanical properties are among the benefits of PE as an active film packaging (AFP) [2]. However, PE film cannot inhibit the bacterial growth on food and also causes environmental issues by increasing the amount of plastic waste disposal in the landfill due to the long-chain structure (non-degradable properties). Therefore, blending PE with antimicrobial agents can improve packaging ability. The additives can convert non-degradable PE film into a partially degradable film.

Several works reported on incorporating additives in PE films such as biopolymers, natural extracts, essential oils, organic acids, enzymes, bacteriocins, fungicides, and others that have the same goal to embed antimicrobial properties of the PE films [3]. The addition of those additives also gives a high contribution to the degradation rate of the film, which lack of studies discussed. Incorporation of zeolites in PE improves the degradation properties of PE because the strong acid sites of zeolites promote the polymer chain cracking (production of low molecular weight hydrocarbon) [4]. Zeolites-silver loaded into PE films function as additives that controlled the release of silver ions from the film to the medium to inhibit the growth of microorganisms, and zeolites-silver did not change the thermal degradation of the film [5]. In other respects, polysaccharide, polypeptides, protein, polynucleotides, and polyester are the natural polymers that had been explored as an agent that able to improve degradation properties but not antimicrobial activities of PE films.

Aloe vera (AV) is a popular material with antimicrobial, antioxidant, and antifungal property, rich in polysaccharides and organic acids [6], [7]. To date, PE and AV have not been formally examined on AV impacts on 
the characteristics and mechanical properties of the PE film. A few studies have been conducted on the impact of AV in starch-based film. Researchers used AV as a cross-linker in the starch-based film to improve the properties [7]. AV gel is added into the formula of film for the application of AFP for wrapping or covering easily spoiled food products such as meat or fresh fruits [6]-[8]. AV able to improves the compatibility between starches and plasticiser because the cross-linking occurred between starches molecules due to the presence of organic acid and polyphenolic compounds in AV [8]. Besides, a combination of AV with plasticiser could form a new film that has the potential to become the raw material for a new film [9].

The organic acid in AV increases the hydrogen bonding interaction and enhances the hydrophobic nature of starch. Thus, it led to the plasticising effect that improves the thickness, solubility, molecular weight, thermal properties, and mechanical behaviour of the starch film [10]-[12]. Incorporation of AV with polyvinyl alcohol and citric acid also promotes the tensile strength of the film [7]. AV was even able to increase the thermal degradation of the film [8] at once, affecting the crystallinity of the film [9]. Therefore, AV gel was added into PE film as additives that able to improve the mechanical properties of the film. To the author's knowledge, there is no study conducted on combining PE-based film with AV gel. The PE films were prepared using a melt blending method incorporated with $\mathrm{AV}$ gel. The films were then characterised by the presence of the functional group, the appearance or changes of crystalline structure, the degradation temperature profile, thermal analysis, and impact of AV on mechanical properties performance.

\section{METHODOLOGY}

\section{Material}

Low-density PE (Lotte Chemical, Titans, Malaysia) and extracted AV Gel (Malaysia) 


\section{Extraction of AV gel}

The AV gel extraction modification method was based on a previous study method [8], [11]. The extraction started with the removal of yellowish liquid from the cut leaves for five to ten minutes. Then, the leaves were cleaned using distilled water, and a paper towel was used to dry it. The leaves were then cut horizontally, and the gel was transferred into a blender. The gel was blended for three minutes and was filtered using cheesecloth to discard the impurities. The permeate was used for blending with PE.

\section{Preparation of the film}

Table 1 shows the formulation of the film. The procedure that applied to produce the film was a modified method that consists of three main steps; 1) melt-blended, 2) crushing, and 3) hot press [8], [13]-[15]. Firstly, the $\mathrm{PE}$ and $\mathrm{AV}$ were pre-mixed in a beaker by manually stirring process for 30 minutes and left for 24 hours in a desiccator. The mixture was then melt blended in a Banbury Thermoo Haake Polylab Internal Mixer at operating condition of $170{ }^{\circ} \mathrm{C}, 60 \mathrm{rpm}$ rotation, and ten minutes duration to form a homogeneous solid resin. Secondly, the solid resin was crushed in Rexmac Compact Crusher to break it down into a smaller size that less than $2 \mathrm{~mm}$. Finally, the crushed resin was compressed using Cometech Hot Press at three phases condition; 1) pre-heat phase, the material was pre-heating at $130{ }^{\circ} \mathrm{C}, 0 \mathrm{psi}$ and ten minutes, 2) hot pressing phase, the material was pressed at $130{ }^{\circ} \mathrm{C}, 700 \mathrm{psi}$ and ten minutes, 3) cooling phase, next to water tab were flowing through the compression plate at 700 psi until reach room temperature. The film was then peeled off from the steel plate.

Table 1: The Formulation of the Film

\begin{tabular}{|l|c|c|}
\hline \multicolumn{1}{|c|}{ Sample name } & PE $(\mathrm{g})$ & AV $(\mathrm{g})$ \\
\hline PE & 60 & 0 \\
\hline PE-AV3 & 58.2 & 1.8 \\
\hline PE-AV5 & 57 & 3 \\
\hline PE-AV7 & 55.8 & 4.2 \\
\hline PE-AV9 & 54.6 & 5.4 \\
\hline
\end{tabular}




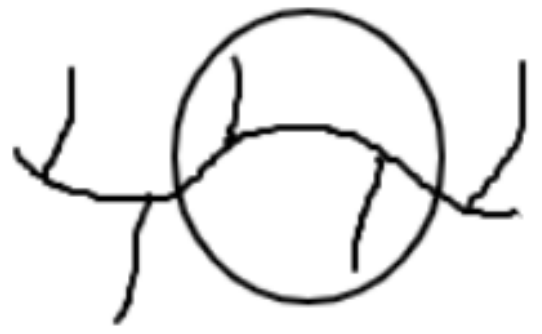

(a)

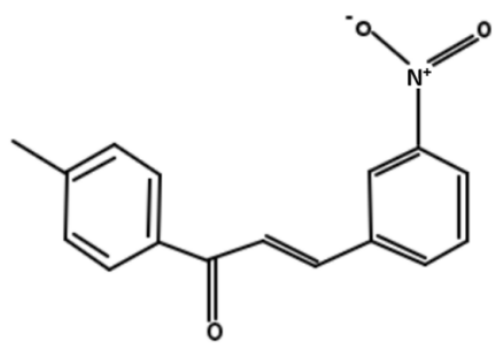

(b)

Figure 1: Structure of (a) PE [16] and (b) AV Gel [17]

\section{Characterisation of the film}

Infrared (IR) spectra of the films were determined using a Fourier Transformed Infrared Spectroscopy (FTIR) spectrophotometer (Mettler Toledo). IR absorbance spectra were collected at the range of frequency between 640 - $4000 \mathrm{~cm}-1$, running time, 64 scans and with $4 \mathrm{~cm}-1$ resolution. Figure 1 shows the chemical structure of $\mathrm{PE}$ and $\mathrm{AV}$ and will help in determining the presence of new functional groups due to the combination of both materials. The films were characterised using an X-ray Diffractometer (XRD) (PANalytical Aeris). The range of diffraction angles (20) was $5-70$, and the scanning rate was $2.1786 \times 10^{-4} 2 \theta \%$ for 25 minutes. The XRD equipped with $\mathrm{CuK}(\alpha)$-radiation filtered by cross-coupled Göbel mirrors at $40 \mathrm{kV}$ and $40 \mathrm{~mA}$. The average crystalline size was calculated based on Scherer's Equation and obtained from the diffractograms. The degree of crystallinity also can be calculated using the same diffractogram but based on equation 1 .

Differential scanning calorimetry (DSC) was used to analyse the thermal properties of the films. The data taken were the melting temperature $\left(\mathrm{T}_{\mathrm{m}}\right)$, crystallisation temperature $\left(\mathrm{T}_{\mathrm{c}}\right)$, enthalpy of fusion/melting $\left(\Delta \mathrm{H}_{\mathrm{m}}\right)$ and enthalpy of crystallisation $\left(\Delta \mathrm{H}_{\mathrm{c}}\right)$. A DSC (Mettler Toledo) was used under the nitrogen atmosphere $(50 \mathrm{ml} / \mathrm{min}$ flowrate). An amount of $5 \mathrm{mg}$ samples was weight, transferred, and sealed in an aluminium pan before undergo three heating processes. The three heating process is also known as cycle process 
involved; 1) first heating ( 25 to $\left.190{ }^{\circ} \mathrm{C}\right), 2$ ) cooling $\left(190\right.$ to $\left.-10{ }^{\circ} \mathrm{C}\right)$ and 3 ) second heating $\left(-10\right.$ to $\left.190{ }^{\circ} \mathrm{C}\right)$ at a heating rate of $20^{\circ} \mathrm{C} / \mathrm{min}$. First heating was designed to erase previous thermal history while the cooling imparts a known thermal history. The Tc obtained from the cooling process at the maximum exothermic peak, and the area of the exothermic curve represents the $\Delta \mathrm{H}_{\mathrm{c}}$. The second heating was related to real internal differences in the material where Tm obtained from the maximum endothermic peak, and $\Delta \mathrm{H}_{\mathrm{m}}$ represents by the area of the endothermic curve.

Thermogravimetric analysis was performed using a Thermal Gravimetric Analyser (TGA) Instrument (TGA/SDTA581, Mettler Toledo). Samples approximately $20 \mathrm{mg}$ were subjected under a nitrogen atmosphere ( $50 \mathrm{ml} / \mathrm{min}$ flowrate), at ranging temperature between 25 to $600{ }^{\circ} \mathrm{C}$, and a constant heating rate of $10^{\circ} \mathrm{C} / \mathrm{min}$. The weight loss represents the material thermal stability and the fraction of the volatile component. The weight loss was calculated based on equation 2, where: Wi is initial weight, and Wf is the final weight.

\section{Mechanical Properties}

A load test was carried out using a Universal Testing Machine (Instron 3382), where the films were strained at a rate of $10 \mathrm{~mm} / \mathrm{min}$, room temperature condition. The samples were cut with a length of $100 \mathrm{~mm}$ and width $25 \mathrm{~mm}$, following requirements from ASTM D882 and strained at a rate of $10 \mathrm{~mm} / \mathrm{min}$, room temperature condition. The $U_{E}$ was measured from the area under the stress-strain curve until the yield point, while $\mathrm{U}_{\mathrm{T}}$ was the area under the curve until the fracture point. 


\section{RESULTS AND DISCUSSION}

\section{Sample Appearances}

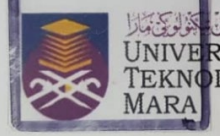

(a)

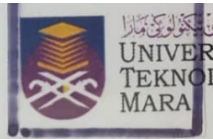

(b)

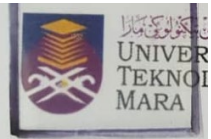

(c)

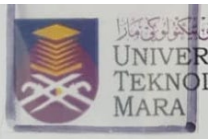

(d)

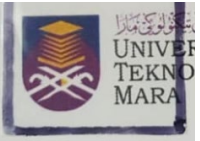

(e)

Figure 2: Photographs Film of a) PE, b) PE-AV3, 3) PE-AV5, 4) PE-AV7 and 5) PE-AV9

Figure 2 shows photographs of PE-AV film. Clear transparency is demonstrated by PE film. The addition of AV did not have a significant impact on the transparency of the film observed by the naked eyes.

\section{Spectroscopy}

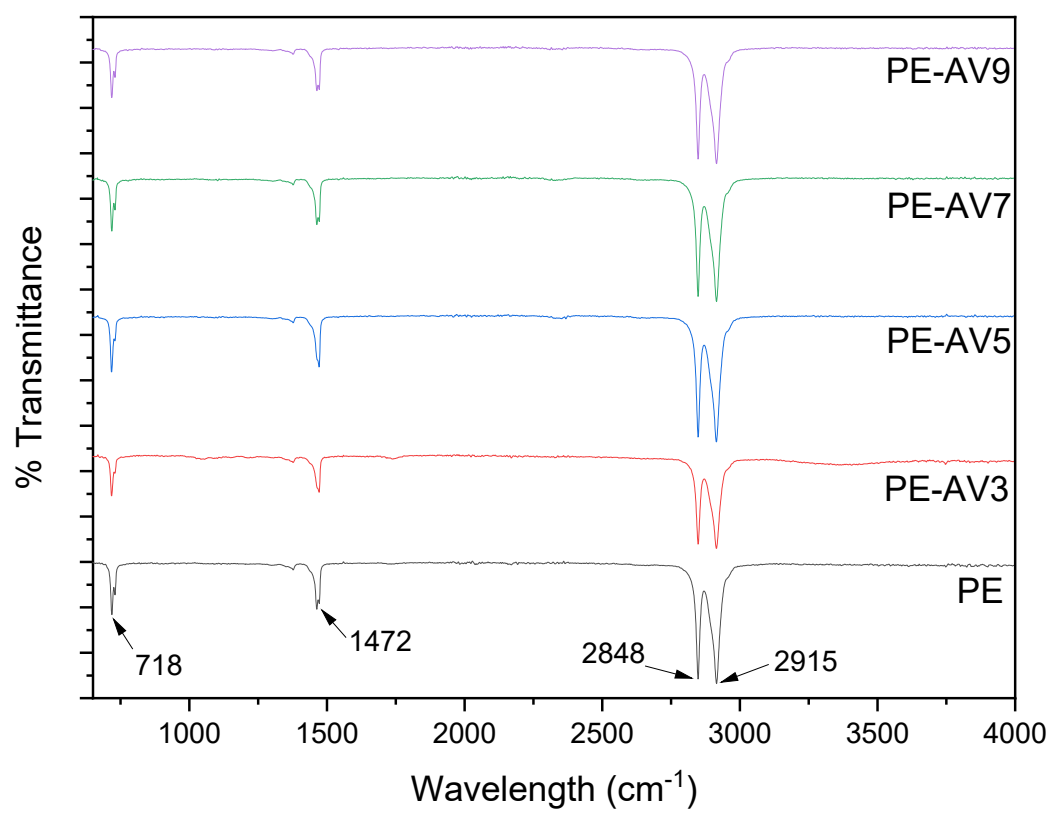

Figure 3: FTIR Spectra of PE and PE-AV Films 
Figure 3 displayed the infrared spectrum for PE and PE-AV films at wavenumber between $640-4000 \mathrm{~cm}^{-1}$. The same peak shows in all films. Four major peaks occurred at $718 \mathrm{~cm}^{-1}$ and $1472 \mathrm{~cm}^{-1}$, which representing strong C-H bending, and medium C-H bending while 2848, and $2915 \mathrm{~cm}^{-1}$ (both representing medium $\mathrm{C}-\mathrm{H}$ stretching). The $\mathrm{C}-\mathrm{H}$ represents the main chemical structure presence in PE. Amelia et al. [18] obtained the same peak representing PE film, where the absorbance bands were located at $2914,2847,1470$, and $718 \mathrm{~cm}^{-1}$ [18]. The typical peaks for AV gel were a broad peak between 3000 and $3600 \mathrm{~cm}^{-1}$ representing the $\mathrm{O}-\mathrm{H}$ stretching and sharp smaller peak at $1635 \mathrm{~cm}^{-1}$ representing the bending mode of free water characteristic. Bajer found that the dried AV formed a broader peak of O-H stretching in between $2500-3600 \mathrm{~cm}^{-1}$, and a small sharp peak obtained around $2900 \mathrm{~cm}^{-1}$ appeared as the medium C-H stretching. Other important peaks also appeared at 1550, 1400,1200, and $1100 \mathrm{~cm}^{-1}$ representing $\mathrm{N}-\mathrm{O}$ stretching, $\mathrm{O}-\mathrm{H}$ bending, and $\mathrm{C}-\mathrm{O}$ stretching, respectively [19]. The fabrication process caused the water to evaporate and caused AV $\mathrm{O}-\mathrm{H}$ stretching and bending, $\mathrm{C}-\mathrm{O}$ stretching and $\mathrm{N}-\mathrm{O}$ stretching disappeared. However, there is a possibility of interaction that happened between these two materials where the sharing peaks obtained at $1472 \mathrm{~cm}^{-1}$ (chemical shifting from 1400 peak of AV shifted to $1472 \mathrm{~cm}^{-1}$ ) and $2915 \mathrm{~cm}^{-1}$ (chemical shifting from 2900 peak of AV shifted to $2915 \mathrm{~cm}^{-1}$ ).

\section{Crystal Structure}

Figure 4 represents the diffractogram intensity of PE and PE-AV films obtained from XRD analysis. The amorphous peak of PE appeared at a diffraction angle of 19.6, and two crystalline peaks occurred at 21.42 and 23.66 diffraction angle. Previous research found the same diffraction angle occurred at 20,21.7, and 24 for pure PE film [20]. The addition of AV into PE films has eliminated all diffraction angles that appeared in PE films, and new diffraction peaks rise at $44.34,51.76$, and 61.73 , respectively. These new peaks change the crystalline structure of PE film, and the intensity of diffractogram PE-AV display lower crystalline peak intensity compared to PE film. For PE-AV films, the intensity of the peak decreasing at the AV concentration increased. The presence of the first peak resulted from the amorphous component in the polymer and usually shown by a broad region intensity [20]. The changes in the PE structure proves that $\mathrm{AV}$ is the 
crystalline structure of PE, and there is chemical bonding between them. From the XRD diffractogram, the crystalline size and degree of crystallinity were calculated and presented in Table 3. From Table 3, the addition of $\mathrm{AV}$ had reduced the degree of crystallinity from $84.07 \%$ to less than $78 \%$, and the lowest is performed by PE-AV9. AV had disturbed the molecule's range order and reduce the periodicity of PE. The less intensity peak of XRD showed by PE-AV9 had root to an imperfect degree of crystallinity. The average crystalline size obtained presents in Table 3 for each film was between 16.03 - 25.13, calculated based on Scherrer's equation.

\section{Thermal Degradation}

Figure 5a displays the TG curves of PE and PE-AV films. It shows that $100 \%$ of degradation occurred at a temperature of more than $496^{\circ} \mathrm{C}$ for all samples. It can be seen that the introduction of AV reduces the decomposition temperature of the PE. The decomposition temperature $\left(\mathrm{T}_{\mathrm{d}}\right)$ is almost the same for each sample except PE-AV3. The $\mathrm{T}_{d}$ of PE-AV3 is $238.35^{\circ} \mathrm{C}$, lower value compared to other films which were between 397 and $403{ }^{\circ} \mathrm{C}$ ). Based on PE-AV3 $\mathrm{T}_{\mathrm{d}}$ value, the PE-AV3 film faced the most responsive condition to the heat. However, the mass loss of $50 \%$ sample shows by the decomposition temperature at $50 \%\left(\mathrm{~T}_{\mathrm{d} 50 \%}\right)$ were about almost the same for all samples; PE-AV5 $\left(468.25^{\circ} \mathrm{C}\right)$, PE-AV7 $\left(470.7{ }^{\circ} \mathrm{C}\right)$, PE-AV3 $\left(472.3^{\circ} \mathrm{C}\right)$, PE-AV9 $\left(476.4^{\circ} \mathrm{C}\right)$, and $\mathrm{PE}\left(481.9^{\circ} \mathrm{C}\right)$. Even though the thermal stability of PE-AV3 was decreased, the film is still stable at a temperature below $200{ }^{\circ} \mathrm{C}$. This validates that the operating condition during melt blending and hot press technique did not cause any thermal degradation to the films. The presence of AV (additives), making a polymer film thermally less stable [21]. The maximum decomposition rates of samples were analysed by using DTG thermograms, as shown in Figure 5b. It was revealed that only one step involved in the thermal degradation of the films. The DTG thermogram of $\mathrm{PE}$ and PE-AV films reveals a peak at maximum temperature $\left(\mathrm{T}_{\max }\right)$ of 470 ${ }^{\circ} \mathrm{C}$ (PE-AV5), $471{ }^{\circ} \mathrm{C}$ (PE-AV3) and $478{ }^{\circ} \mathrm{C}$ (PE, PV-AV7, and PE-AV9) which represents the decomposition of $\mathrm{PE}$ and AV. Similar results obtained when nanoparticles added to $\mathrm{PE}$, the $\mathrm{T}_{\text {max }}$ did not significantly change [22]. The highest weight reduction was experienced by PE-AV5 $(0.61 \mathrm{mg} / \mathrm{min})$ followed by, PE-AV7 (0.6 mg/min), PE-AV3 (0.51 mg/min), PE-AV-9 (0.46 $\mathrm{mg} / \mathrm{min})$. Based on the results, it is validated that the modification of PE by the addition of $\mathrm{AV}$ does affect the rate of weight reduction. 
SCIENTIFIC RESEARCH JOURNAL

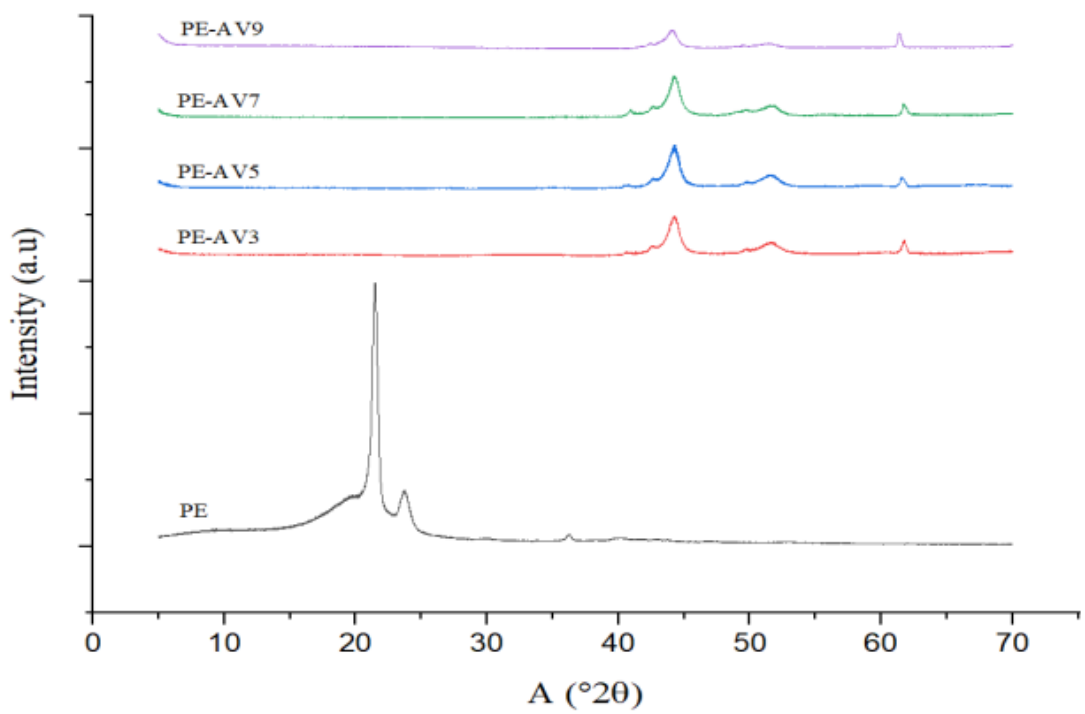

Figure 4: XRD Pattern of PE at Different Concentration of AV gel

Table 3: Crystallise Size and Degree of Crystallinity

\begin{tabular}{|l|c|c|}
\hline \multicolumn{1}{|c|}{ Sample } & Average Crystallise Size (nm) & Degree of crystallinity (\%) \\
\hline PE & 19.32 & 84.07 \\
\hline PE-AV3 & 22.01 & 76.94 \\
\hline PE-AV5 & 25.13 & 76.83 \\
\hline PE-AV7 & 17.80 & 77.90 \\
\hline PE-AV9 & 16.03 & 70.53 \\
\hline
\end{tabular}




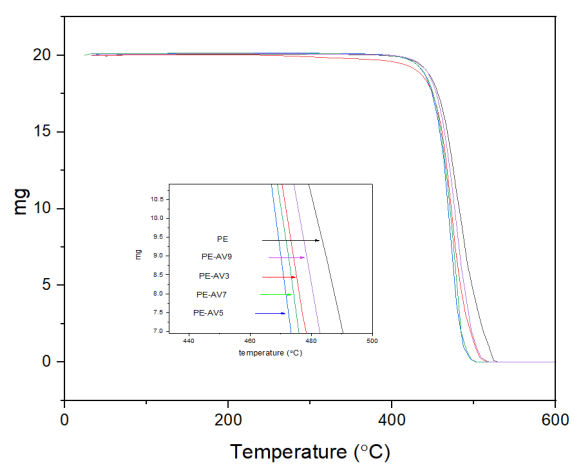

(a)

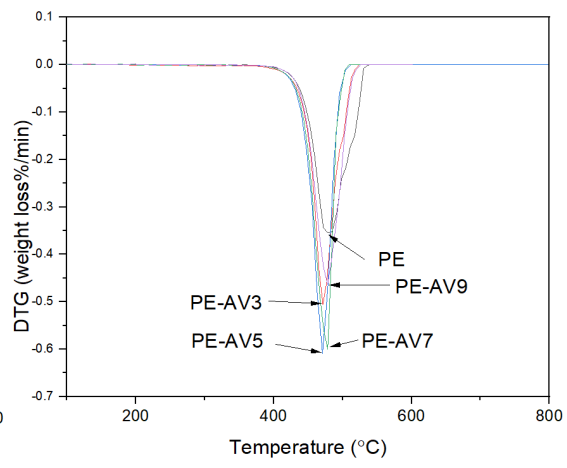

(b)

Figure 5: a) Thermogravimetrics (TG) b) Derivative Thermogravimetric (DTG) Curves of PE at Different Concentration of AV Gel

\section{Thermal Analysis}

Figure $3 a$ ) and $3 b$ ) represents the heating and cooling curve for PE and PE-AV films obtained from DSC analysis. The peak derived from the heating curve determines the melting temperature $\left(\mathrm{T}_{\mathrm{m}}\right)$. In contrast, the peak from the cooling curve gives the crystallisation temperature $\left(\mathrm{T}_{\mathrm{c}}\right)$, and the value is tabulated in Table 2 along with enthalpy of fusion $\left(\Delta \mathrm{H}_{\mathrm{m}}\right)$ and enthalpy of crystallisation $\left(\Delta \mathrm{H}_{\mathrm{c}}\right)$. The results show that there were no significant changes in $\mathrm{T}_{\mathrm{m}}$ and $\mathrm{T}_{\mathrm{c}}$ when $\mathrm{AV}$ was added into PE film. It justifies that weak interactions present between polymer and $\mathrm{AV}$, as also stated by other researchers [21]. The decrease of Tc might due to low interaction between the hydroxyl group of $\mathrm{PE}$ and 5\% AV at once increase the flexibility of the polymeric chain. AV did not show huge differences in $\mathrm{T}_{\mathrm{c}}$ value, thus indicates the low nucleating effect on PE film. If the nucleating agent had a good result, the crystallinity would increase, and $\mathrm{T}_{\mathrm{m}}$ also increased [23]. Linares et al. found the same impact of additives to polypropylene film, where weak interaction between molecular segments of the components resulted in high interfacial tension (at the molten stage) lead to no changes in thermal properties of the film (poor dispersion of particles) [24]. 
The value of $\Delta \mathrm{H}_{\mathrm{m}}$ was obtained from the area under the heating curve while $\Delta \mathrm{Hc}$ from the area under the cooling curve. At $5 \%$ of $\mathrm{AV}$, there are slightly small changes of temperature for $\mathrm{T}_{\mathrm{c}}\left(0.7^{\circ} \mathrm{C}\right.$ reduction $)$, but somewhat affecting the value of $\Delta \mathrm{H}_{\mathrm{c}}$. An abnormal result of $\Delta \mathrm{H}_{\mathrm{c}}$ obtained at $5 \% \mathrm{AV}$, where less energy released to crystallise the material. The thermal properties of PE were influenced by the kinetics of crystallisation during cooling and the reduction of $\mathrm{Tc}$ at $5 \% \mathrm{AV}$. When the $\mathrm{T}_{\mathrm{c}}$ decreased, the number of nuclei per unit volume also decreased [23]. The slight decrement of Tc occurred at $5 \% \mathrm{AV}$, and simultaneously, the $\Delta \mathrm{H}_{\mathrm{c}}$ reduced. This phenomenon suggests that at $5 \% \mathrm{AV}$, there is a possibility of self-nucleation of PE being destroyed and saturated. There is a possibility of the macromolecular movement speeding up and prevent the growth of polymeric crystals around the small nuclei [24].

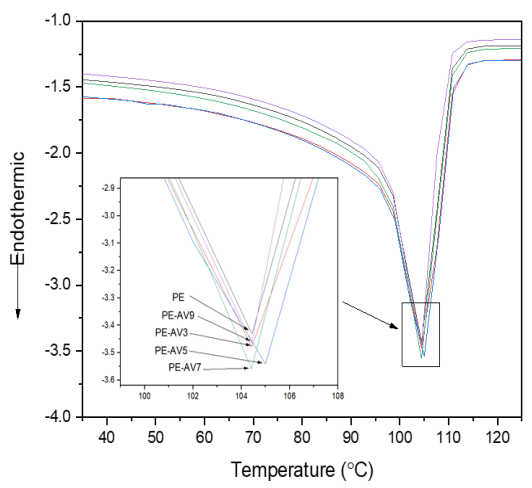

(a)

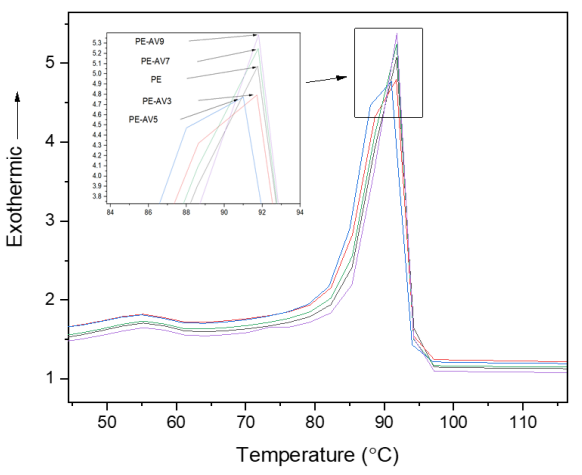

(b)

Figure 6: DSC Curve of a) Heating and b) Cooling for PE and PE-AV Films 
Table 2: DSC Data of PE-AV Films

\begin{tabular}{|l|c|c|c|c|}
\hline Sample Film & $\mathbf{T}_{\mathrm{c}}\left({ }^{\circ} \mathbf{C}\right)$ & $\mathbf{T}_{\mathrm{m}}\left({ }^{\circ} \mathrm{C}\right)$ & $\Delta \mathbf{H}_{\mathrm{m}}(\mathbf{J} / \mathbf{g})$ & $\Delta \mathbf{H}_{\mathrm{c}}(\mathbf{J} / \mathbf{g})$ \\
\hline PE & 91.76 & 104.44 & 133.57 & 88.56 \\
\hline PE-AV3 & 91.72 & 104.43 & 139.96 & 85.01 \\
\hline PE-AV5 & 91.00 & 105.00 & 123.18 & 57.16 \\
\hline PE-AV7 & 91.78 & 104.42 & 141.92 & 92.43 \\
\hline PE-AV9 & 91.80 & 104.44 & 134.63 & 84.62 \\
\hline
\end{tabular}

\section{Mechanical Properties}

Stress-strain curve for the films is shown in Figure 7. The ductile stress-strain profile is displayed by each film, where the stress increase until it achieved a point that the stress stable for a certain time and it sustain the elongation more than $50 \%$ before slowly ruptured. The maximum breaking extension is achieved by PE-AV7, followed by PE-AV5, PE, PE-AV3, and finally PE-AV9. Table 4 summarises the TS, EAB, YM, UE, and UT. PE-AV3 is having the highest value of TS and YM, while PE-AV7 has the highest elongation at break (EAB), 77.67\%. Increasing TS and YM of PE$\mathrm{AV} 3$ could be due to low free volume and the presence of cross-linking with PE molecular structure. The possibility of the reaction occurred between AV and PE, also supported by the crystalline structure changes shown by $\mathrm{XRD}$ results.

However, the reduction of TS occurred with more amount of AV might be due to AV facilitated the sliding of PE chains and lowered the secondary linking forces between the polymer chain. The finding by Jusoh [24] stated that the addition of other materials that able to cause a lubricating effect would reduce the TS of PE film. These results were supported by other research that found the presence of other material in PE disturbs the PE chain structure at once reduced the mechanical properties [21]. The EAB value of PE-AV film increased compared to PE film but sudden drops at $9 \%$ AV. This might occur due to the high amount of AV cause poor adhesion between AV and PE. This result supported by the XRD peak for PE-AV9 that shows low-intensity peak if compared to other PE-AV films. The interfacial adhesion between two polymer matrix plays an important role in the EAB of the polymer [25]. Usually, high TS polymer will give high stiffness and toughness to the material because of the intermolecular forces high. The 
stiffness could be related to the EAB value. Increasing EAB shows low stiffness of material where the presence of $7 \% \mathrm{AV}$ reduces intermolecular forces within the polymer chain, hence improve the mobility and flexibility of the polymer structure [21]. The highest value of $U_{E}$ and $U_{T}$ was obtained by PE-AV3, and the presence of AV shows better value compared to $\mathrm{PE}$ alone except for PE-AV9. Similar results proved that the addition of copolymer or other filler at a certain percentage between $1.5-5 \%$ could improve the toughness characteristic of PE film [26]. The $U_{E}$ and $U_{T}$ values were affected by phase morphology, chain structure, and interfacial adhesion [27].

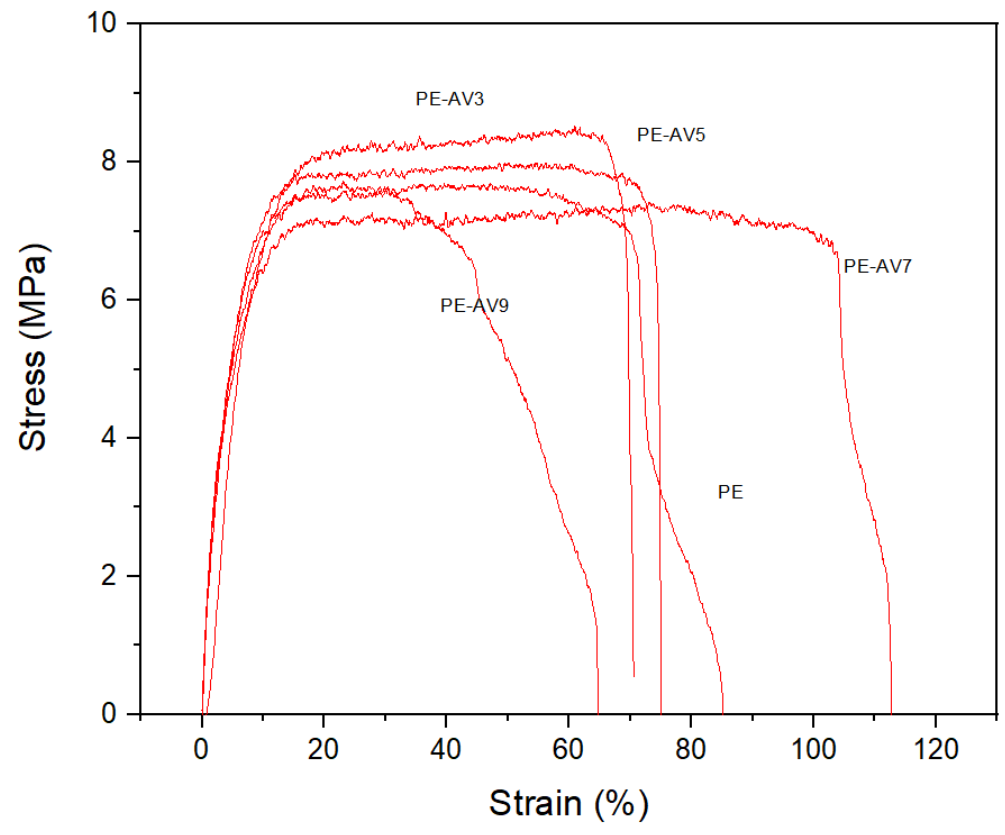


Table 4: Mechanical Properties of the Films

\begin{tabular}{|l|l|l|l|l|l|}
\hline Film & $\begin{array}{l}\text { TS } \\
(\mathrm{MPa}), \\
\sigma\end{array}$ & EAB (\%) & YM (MPa), $\varepsilon$ & $\begin{array}{l}\text { Modulus of } \\
\text { Resilience }(\mathrm{MJ} / \\
\mathrm{m3}), \mathrm{U}_{\mathrm{E}}\end{array}$ & $\begin{array}{l}\text { Modulus of } \\
\text { Toughne s } \\
\left(\mathrm{MJ} / \mathrm{m}^{3}\right), \mathrm{U}_{\mathrm{T}}\end{array}$ \\
\hline PE & 7.79 & 52.20 & 122.03 & 9.87 & 279.76 \\
\hline PE-AV3 & 9.09 & 55.60 & 124.48 & 17.70 & 492.73 \\
\hline PE-AV5 & 8.31 & 54.67 & 95.58 & 11.36 & 361.46 \\
\hline PE-AV7 & 7.80 & 77.67 & 103.41 & 16.29 & 428.47 \\
\hline PE-AV9 & 8.00 & 18.20 & 121.30 & 7.83 & 126.54 \\
\hline
\end{tabular}

\section{CONCLUSION}

The PE films consist of AV as an additive were successfully prepared using melt blending and hot press technique. PE-AV3 was the best film with the highest tensile strength. Crystal structure and mechanical properties show significant differences after the addition of AV to PE films. The specific concentration of AV gave the highest value of the TS, YM, UE, and UT and contributing to lowering the thermal degradation temperature. There were no huge differences in the functional group peaks (spectroscopy) and thermal properties (Tm, Tc, and enthalpy). The primary outcome shows that TS plays an essential role in this study because it indicates that low PE content with a certain amount of AV can improve the performance of TS. Therefore, AV has excellent potential to be one of the additives in the future development of AFP.

\section{ACKNOWLEDGEMENT}

Special thanks to Polymer Lab, Faculty of Chemical Engineering, UiTM Shah Alam, and Faculty of Mechanical Engineering, UiTM Shah Alam for the facilities. Appreciation to research grant (FRGS/1/2018/TK02/ UITM/02/9) for the budget provided for this study. 


\section{REFERENCES}

[1] FBI101584, "Polyethylene (PE) market," 2019. [Online]. Available: https://www.fortunebusinessinsights.com/industry-reports/ polyethylene-pe-market-101584.

[2] N. Khanoonkon, R. Yoksan, and A. A. Ogale, "Morphological characteristics of stearic acid-grafted starch-compatibilized linear low density polyethylene/thermoplastic starch blown film," Eur. Polym. J., 76, pp. 266-277, 2016.

[3] B. Malhotra, A. Keshwani, and H. Kharkwal, "Antimicrobial food packaging: Potential and pitfalls," Front. Microbiol., 6, no. JUN, 2015.

[4] A. O. S. Silva, M. J. B. Souza, A. M. G. Pedrosa, A. C. F. Coriolano, V. J. Fernandes, and A. S. Araujo, "Development of HZSM-12 zeolite for catalytic degradation of high-density polyethylene," Microporous Mesoporous Mater., 244, pp. 1-6, 2017.

[5] D. L. Boschetto, L. Lerin, R. Cansian, S. B. C. Pergher, and M. Di Luccio, "Preparation and antimicrobial activity of polyethylene composite films with silver exchanged zeolite-Y," Chem. Eng. J., 204-205, pp. 210-216, 2012.

[6] G. F. El Fawal, A. M. Omer, and T. M. Tamer, "Evaluation of antimicrobial and antioxidant activities for cellulose acetate films incorporated with Rosemary and Aloe Vera essential oils," J. Food Sci. Technol., 56, no. 3, pp. 1510-1518, 2019.

[7] S. R. Kanatt and S. H. Makwana, "Development of active, waterresistant carboxymethyl cellulose-poly vinyl alcohol-Aloe vera packaging film," Carbohydr. Polym., 227, no. (September) 2019, p. 115303, 2020.

[8] T. J. Gutiérrez and K. Álvarez, "Physico-chemical properties and in vitro digestibility of edible films made from plantain flour with added Aloe vera gel," J. Funct. Foods, 26, pp. 750-762, 2016. 
[9] R. Ortega-Toro, S. Collazo-Bigliardi, J. Roselló, P. Santamarina, and A. Chiralt, "Antifungal starch-based edible films containing Aloe vera," Food Hydrocoll., 72, pp. 1-10, 2017.

[10] T. J. Gutiérrez and G. González, "Effect of Cross-Linking with Aloe vera Gel on Surface and Physicochemical Properties of Edible Films Made from Plantain Flour," Food Biophys., 12, no. 1, pp. 11-22, 2017.

[11] M. I. Pinzon, O. R. Garcia, and C. C. Villa, "The influence of Aloe vera gel incorporation on the physicochemical and mechanical properties of banana starch-chitosan edible films," J. Sci. Food Agric., 98, no. 11, pp. 4042-4049, 2018.

[12] S. Khoshgozaran-Abras, M. H. Azizi, Z. Hamidy, and N. BagheripoorFallah, "Mechanical, physicochemical and color properties of chitosan based-films as a function of Aloe vera gel incorporation," Carbohydr. Polym., 87, no. 3, pp. 2058-2062, 2012.

[13] S. H. Kamarudin, E. R. Jusoh, L. C. Abdullah, M. H. S. Ismail, M. M. Aung, and C. T. Ratnam, "Thermal and Dynamics Mechanical Analysis of Polypropylene Blown Films with Crude Palm Oil as Plasticizer," Indones. J. Chem., 19, no. 3, p. 545, 2019.

[14] C. T. Ratnam, A. M. Min, T. G. Chuah, A. R. Suraya, T. S. Y. Choong, and W. H. W. Hasamuddin, "Physical properties of polyethylene modified with crude palm oil," Polym. - Plast. Technol. Eng., 45, no. 8, pp. 917-922, 2006.

[15] M. Younesi et al., "Surface functionalization of extracted nanosilica from rice husk for augmenting mechanical and optical properties of synthesized LDPE-Starch biodegradable film," J. Clean. Prod., 31, no. April, pp. 1153-1161, 2019.

[16] "Low-density polyethylene." [Online]. Available: https://www. britannica.com/science/low-density-polyethylene.

[17] "Aloe vera." [Online]. Available: https://www.chemicalbook.com/ ChemicalProductProperty_EN_cb3484483.htm. 
[18] R. P. D. Amelia, S. Gentile, W. F. Nirode, and L. Huang, "Quantitative Analysis of Copolymers and Blends of Polyvinyl Acetate (PVAc) Using Fourier Transform Infrared Spectroscopy (FTIR) and Elemental Analysis (EA)," World J. Chem. Educ., 4, no. 2, pp. 25-31, 2016.

[19] D. Bajer, K. Janczak, and K. Bajer, "Novel Starch/Chitosan/Aloe Vera Composites as Promising Biopackaging Materials," J. Polym. Environ., 28(3), pp. 1021-1039, 2020.

[20] G. Tadayyon, S. M. Zebarjad, and S. A. Sajjadi, "Effect of both nano-size alumina particles and severe deformation on polyethylene crystallinity index," J. Thermoplast. Compos. Mater., 25(4), pp. 479-490, 2012.

[21] R. J. Solano, C. A. Sierra, and M. Ávila Murillo, “Antifungal activity of LDPE/lauric acid films against Colletotrichum tamarilloi," Food Packag. Shelf Life, 24, February, p. 100495, 2020.

[22] N. Amigo et al., "Effect of starch nanoparticles on the crystallization kinetics and photodegradation of high density polyethylene," Compos. Part B Eng., 174, October 2018, 2019.

[23] X. L. Wang, K. K. Yang, Y. Z. Wang, D. Y. Wang, and Z. Yang, "Crystallization and morphology of a novel biodegradablepolymer system: Poly(1,4-dioxan-2-one)/starch blends," Acta Mater., 52, 16, pp. 4899-4905, 2004.

[24] A. Moeini et al., "Thermoplastic starch and bioactive chitosan sub-microparticle biocomposites: Antifungal and chemico-physical properties of the films," Carbohydr. Polym., 230, August 2019, pp. $1-9,2020$.

[25] N. A. Ramlee and Y. Tominaga, "Mechanical and degradation properties in alkaline solution of poly(ethylene carbonate)/poly(lactic acid) blends," Polymer (Guildf)., 166, September 2018, pp. 44-49, 2019.

[26] N. J. Arne O. Finberg, Edison, “H-NH,” 1978. 
[27] O. A. Bin-Dahman, J. Jose, and M. A. Al-Harthi, "Compatibility of poly(acrylic acid)/starch blends," Starch/Staerke, 67, no. 11-12, pp. 1061-1069, 2015. 